\title{
Effect of Processing on Nutritional Quality of Spinach (Spinacia oleracea)
}

\author{
Anupam Ghosh \\ Department of Food Technology and Biochemical Engineering \\ Jadavpur University \\ Uma Ghosh \\ Department of Food Technology and Biochemical Engineering \\ Jadavpur University
}

\begin{abstract}
Fruits and vegetables contain significant levels of biologically active components that result health benefits beyond basic nutrition. Spinach is considered as one of the most nutritious vegetables. It is the excellent source of phytochemicals. Investigations were carried out to study the effect of drying on total phenol content, antioxidant property of dehydrated spinach. The dehydration of spinach was done at $50^{\circ} \mathrm{C}, 60^{\circ} \mathrm{C}, 70^{\circ} \mathrm{C}$ for 4 hours using tray drier. For tray drying the drying rate increased with increased temperature but decreased with increase in time. Pretreatment showed insignificant effect on quality of dehydrated spinach. In addition, Freeze drying resulted in products with better quality characteristic of dehydrated spinach. The experimental drying data of spinach was applied to Newton model.
\end{abstract}

Keywords -Tray drying, Freeze drying, Total phenol content, Antioxidant capacity, Moisture content etc.

\section{INTRODUCTION}

Epidermiological studies have revealed that intake of vegetables reduces the risk of cancer and cardiovascular diseases ${ }^{1}$.This beneficial effect on human health is attributed due to the presence of different antioxidant components such as vitamins, polyphenols and phytochemicals in vegetables ${ }^{2}$.

Spinach (Spinacia oleracea), the cool annual leafy vegetable is considered to have a high nutritional value ${ }^{3}$. It is a rich source of vitamins, minerals and dietary fibers ${ }^{4,5}$, Carotenoids, Flavonoids and polyphenols ${ }^{6,7}$.

Drying is the one of the widespread methods of preservation of agricultural products ${ }^{8}$

The reduction in moisture content not only helps in increasing the shelf life of the commodity but reduces the weight and volume. Therefore minimizing packing and also storage and transportation cost ${ }^{9}$. However thermal processing can affect nutritional quality and also acceptability of the processed spinach. Retention of the nutritive features plays a considerable role in overall acceptability of thermally processed vegetables ${ }^{10}$. Therefore the present investigation was made to study the drying characteristics of spinach at various temperatures along with changes in polyphenol and antioxidant capacity of pretreated spinach during processing.

There are different ways to model drying processes, which is a necessary part for the development energy efficient drying techniques. Mathematical modeling is important to improve the performance of drying system ${ }^{11}$. An attempt was made to apply the experimental drying data on Newton model ${ }^{12}$ to describe the behavior of spinach and develop a drying equation.

\section{MATERIALS AND METHODS}

Fresh spinach leaves were procured from local market. The leaves were washed thoroughly with tap water to remove adhering dust. The surface moisture on the wet sample was removed with a muslin cloth. The samples were then subjected to following parameters:

1) Spinach leaves without any blanching were considered as control

2) Water blanching $(1: 5 \mathrm{w} / \mathrm{v})$ prior drying

3) Salt blanching $(1: 5 \mathrm{w} / \mathrm{v})$ with saline solution $(2 \% \mathrm{NaCl})$ prior drying

Spinach leaves were dipped in boiling water and salt solution $(2 \% \mathrm{NaCl})$ respectively for $2-3$ minutes followed by cooling with cold water. Each pretreatment sample was divided into two parts. One part was dried in tray drier at different temperatures. The other part was dried at freeze drier. Drying 
experiments were performed by tray drier at $50^{\circ} \mathrm{C}, 60^{\circ} \mathrm{C}, 70^{\circ} \mathrm{C}$ for 4 hours. Samples were taken at $1 \mathrm{hr}$ interval and analyzed for moisture content, total phenol content and FRAP analysis.

Analytical parameters:

Moisture content was determined according to method described by Ranganna ${ }^{13}(1986)$.

Total phenolic content was determined by Folin-Ciocalteu method ${ }^{14}$ at a wavelength of $765 \mathrm{~nm}$ and expressed as $\mathrm{mg}$ of Gallic acid/mg of spinach.

Antioxidant capacity of spinach sample was estimated according to the procedure described by Benzie and Strain ${ }^{15}$ as modified by Pulido, Bravo, and Saura-Calixto ${ }^{16}$ at a wavelength of $593 \mathrm{~nm}$ using a spectrophotometer (Hitachi U2000).

The value of MR moisture ratio is calculated by the method developed by Henderson ${ }^{17}$ and Perry (1976)

\section{$M A R=\frac{M=N_{k}}{N_{i}-M_{i}}$}

Where, $\mathrm{M}_{\mathrm{i}}$ and $\mathrm{M}$ are the moisture content $(\% \mathrm{db})$ at initial and final time respectively.

Since during drying, the samples were not exposed to uniform relative humidity and temperature continuously. Therefore, moisture ratio was simplified according to Doymez ${ }^{18}$ and Goyal ${ }^{19}$ and expressed as

From Newton equation,

$$
M R=\frac{M}{M l}
$$

\section{MNR $=e^{-h i}$}

Therefore,

\section{$\ln M R R=-k t$}

Then the graph was plotted ln MR vs time (in hr).

\section{RESULTS AND DISCUSSION}

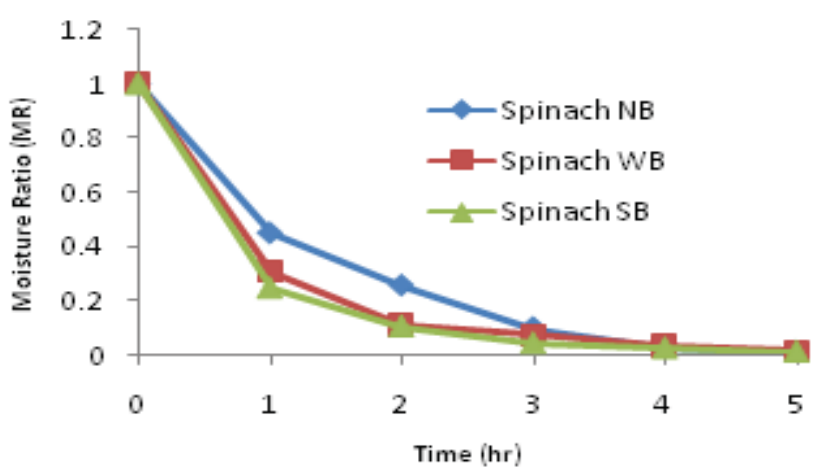

Fig 1a.Effect of thermal treatment of spinach on tray drying at $50^{\circ} \mathrm{C}$

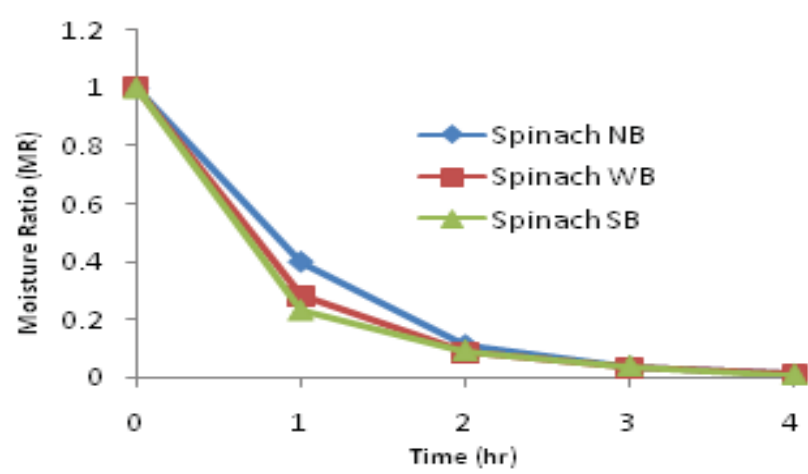

Fig 1 b.Effect of thermal treatment of spinach on tray drying at $60^{\circ} \mathrm{C}$

Moisture ratio vs Time curves for tray drying at $50^{\circ} \mathrm{C}, 60^{\circ} \mathrm{C}, 70^{\circ} \mathrm{C}$ are shown in Fig1a, Fig $1 \mathrm{~b}$ and Fig $1 \mathrm{c}$ respectively. At $50^{\circ} \mathrm{C}$ curves shows the decreasing trend of drying process. After completion of drying maximum moisture ratio was observed with Non-blanching control sample (NB)(0.0119) than water blanching sample (WB) $(0.0113)$ than that of salt blanching sample(SB)(0.00984). Similar result was observed at $60^{\circ} \mathrm{C}$ and $70^{\circ} \mathrm{C}$. At $60^{\circ} \mathrm{C}$ maximum moisture ratio was observed with control (0.0118) than water blanching sample (0.00893) than that of salt blanching sample $(0.00809)$. At $70^{\circ} \mathrm{C}$ maximum moisture ratio was observed with control $(0.0102)$ than water blanching sample (0.00773) than that of salt blanching sample (0.00748). 


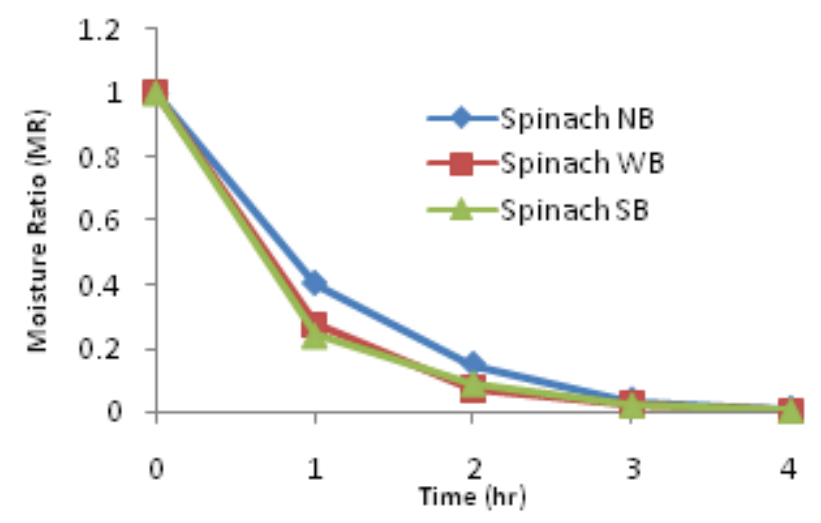

Fig 1c.Effect of thermal treatment of spinach on tray drying at $70^{\circ} \mathrm{C}$

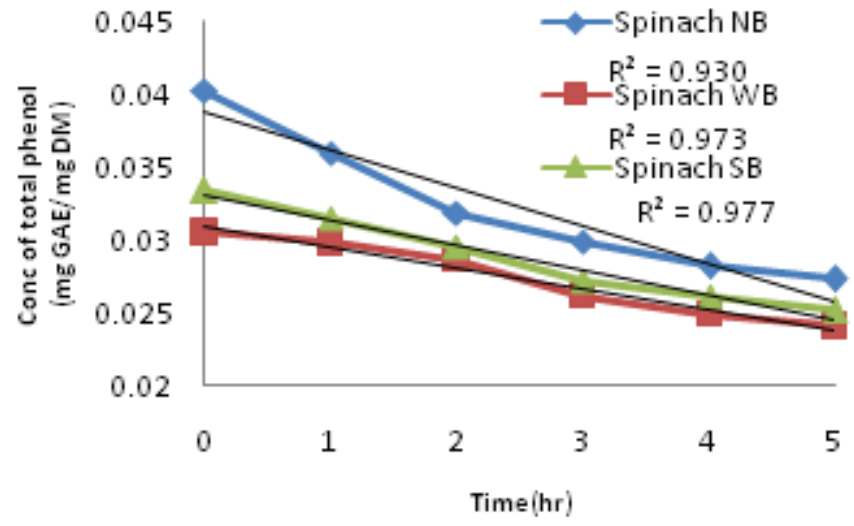

Fig 2a.Effect of thermal treatment of spinach on total phenol content at $50^{\circ} \mathrm{C}$

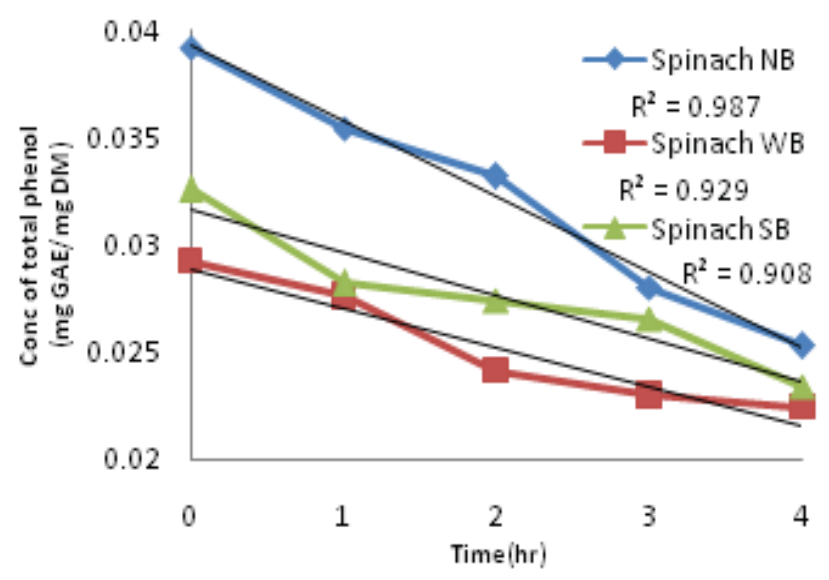

Fig $2 \mathrm{~b}$.Effect of thermal treatment of spinach on total phenol content at $60^{\circ} \mathrm{C}$

Fig2a,2b,2c represents of effect of thermal treatment on total phenol content of control (non-blanching), water blanching and blanching with salt solution $(2 \% \mathrm{Nacl})$ spinach sample at $50^{\circ} \mathrm{C}, 60^{\circ} \mathrm{C}, 70^{\circ} \mathrm{C}$ respectively. At $50^{\circ} \mathrm{C}$ control (non-blanching) spinach sample (NB) has highest total phenol content [0.0273] (mg GAE/mg DM) than water blanching (WB) [0.0241] (mg GAE/mg DM) and blanching with salt solution (2\%Nacl) spinach sample (SB) [0.0252] (mg GAE/mg DM) after completion of drying. Similar result was observed at $60^{\circ} \mathrm{C}$ and $70^{\circ} \mathrm{C}$. At $60^{\circ} \mathrm{C}$ highest total phenol content was observed in control sample [0.0253] (mg GAE/mg DM) than water blanching sample [0.0224] (mg GAE/mg DM) than that of salt blanching sample [0.0234] (mg GAE/mg DM). At $70^{\circ} \mathrm{C}$ maximum total phenol content was observed with control sample [0.0245] (mg GAE/mg DM) than water blanching sample [0.0220] (mg GAE/mg DM) than that of salt blanching sample [0.0228] (mg GAE/mg DM). 


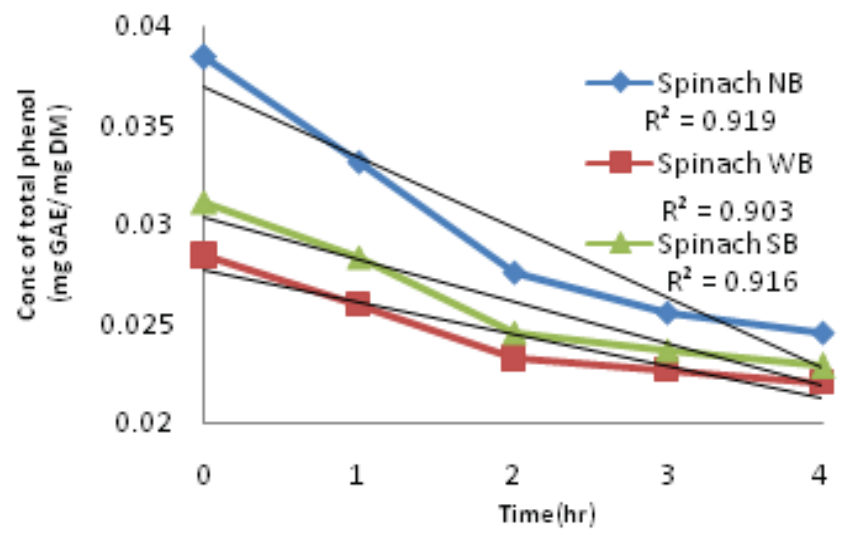

Fig 2c.Effect of thermal treatment of spinach on total phenol content at $70^{\circ} \mathrm{C}$

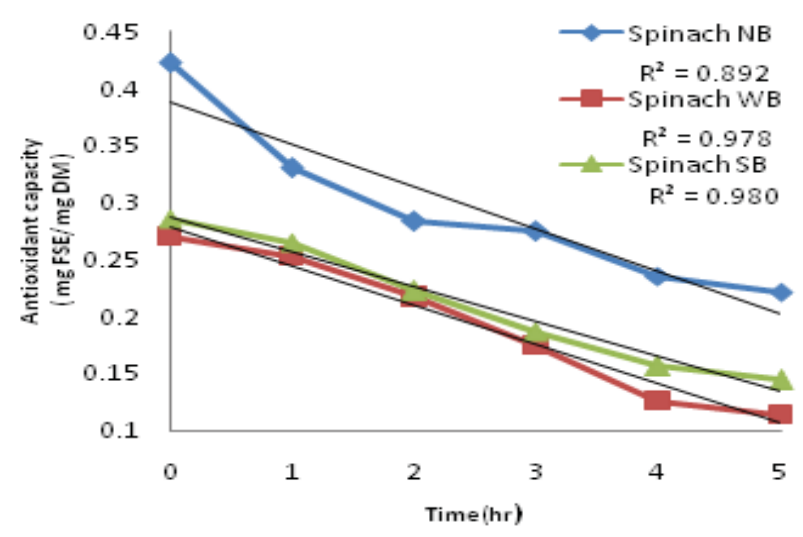

Fig 3a.Effect of thermal treatment of spinach on antioxidant activity at $50^{\circ} \mathrm{C}$

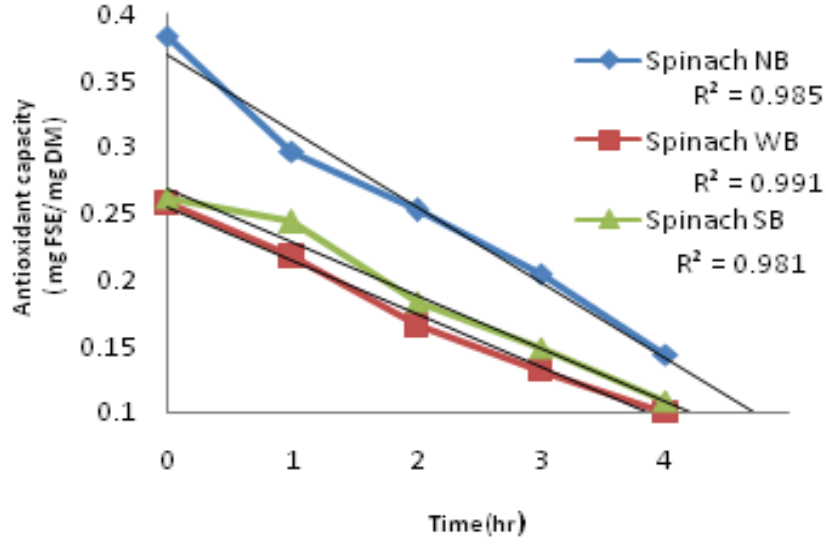

Fig $3 b . E f f e c t$ of thermal treatment of spinach on antioxidant activity at $60^{\circ} \mathrm{C}$

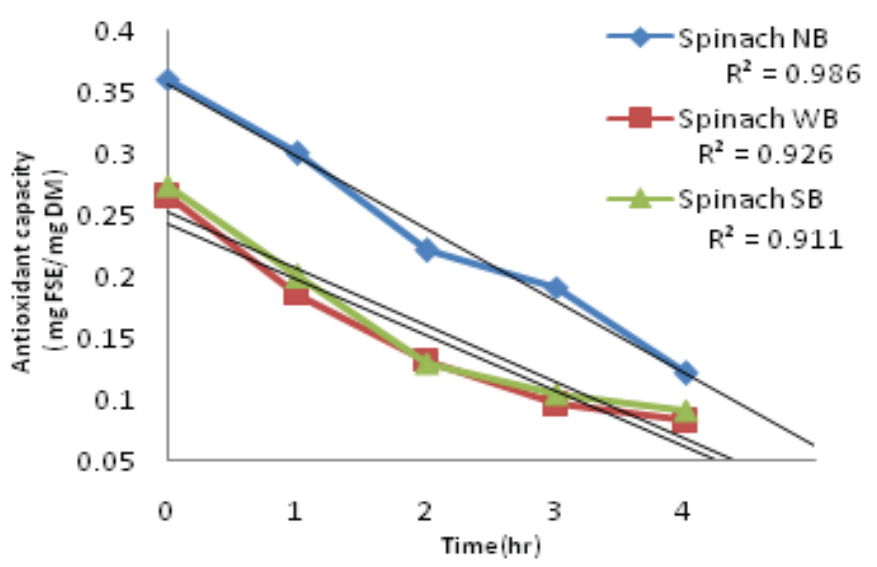

Fig 3c.Effect of thermal treatment of spinach on antioxidant activity at $70^{\circ} \mathrm{C}$

Fig3a,3b,3c represents of effect of thermal treatment on antioxidant capacity of control (non-blanching),water blanching and blanching with salt solution $(2 \% \mathrm{Nacl})$ spinach sample at $50^{\circ} \mathrm{C}, 60^{\circ} \mathrm{C}, 70^{\circ} \mathrm{C}$ respectively. At $50^{\circ} \mathrm{C}$ control (non-blanching) spinach sample(NB) has highest antioxidant capacity [0.221] (mg FSE/mg DM) than water 
blanching(WB) [0.113] (mg FSE/mg DM) and blanching with salt solution (2\%Nacl) spinach sample(SB) [0.144] (mg FSE/mg DM) after completion of drying. Similar result was observed at $60^{\circ} \mathrm{C}$ and $70^{\circ} \mathrm{C}$. At $60^{\circ} \mathrm{C}$ highest antioxidant capacity was observed in control sample [0.143] (mg FSE/mg DM) than water blanching sample [0.100] (mg FSE/mg DM) than that of salt blanching sample [0.108] (mg FSE $/ \mathrm{mg} \mathrm{DM}$ ). At $70^{\circ} \mathrm{C}$ maximum antioxidant capacity was observed with control sample [0.121] (mg FSE/mg DM) than water blanching sample [0.0826] (mg FSE/mg DM) than that of salt blanching sample [0.0913] (mg FSE/mg DM).

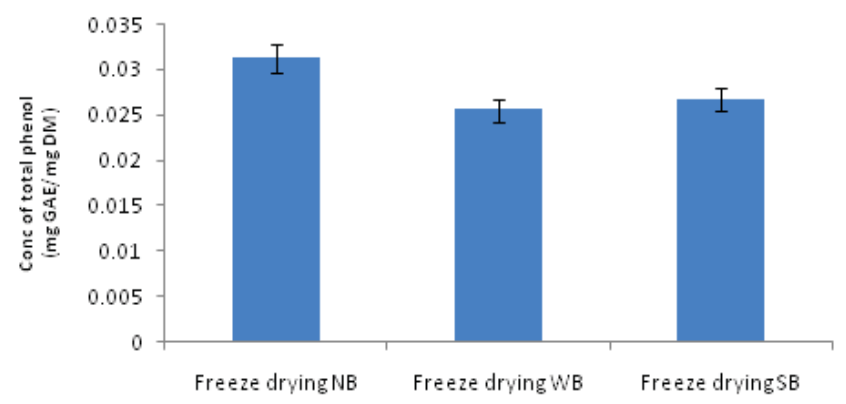

Fig4a. Total Phenol content of pretreated freeze dried spinach samples (NB-Control, WB-Water blanched and SB-blanching with salt solution)

Total phenol content of freeze dried control (non-blanching) spinach sample [0.0313] (mg GAE/mg DM) was highest than that of water-blanching [0.0255] (mg GAE/mg DM) and blanching with salt solution (2\%Nacl) spinach sample [0.0267] (mg GAE/mg DM).

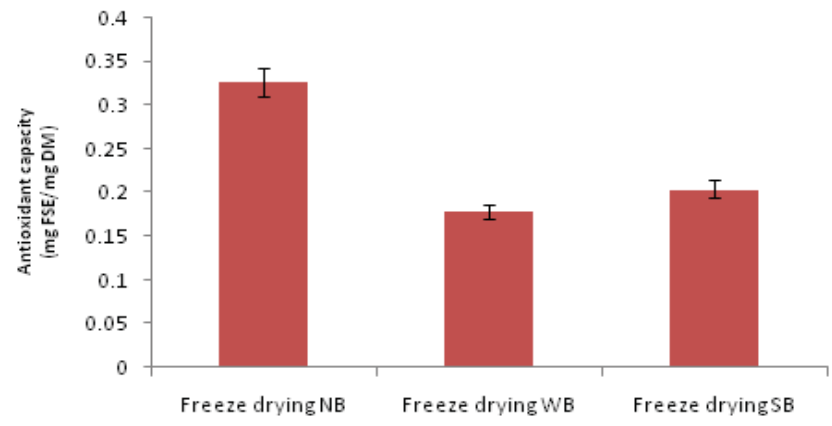

Fig4b. Antioxidant capacity of pretreated freeze dried spinach samples (NB-Control, WB-Water blanched and SB-blanching with salt solution)

Total Antioxidant capacity of freeze dried control (non-blanching) spinach sample [0.326] (mg FSE/mg DM) was highest than that of water-blanching [0.178] (mg FSE/mg DM) and blanching with salt solution (2\%Nacl) spinach sample [0.204] (mg FSE/mg DM). 


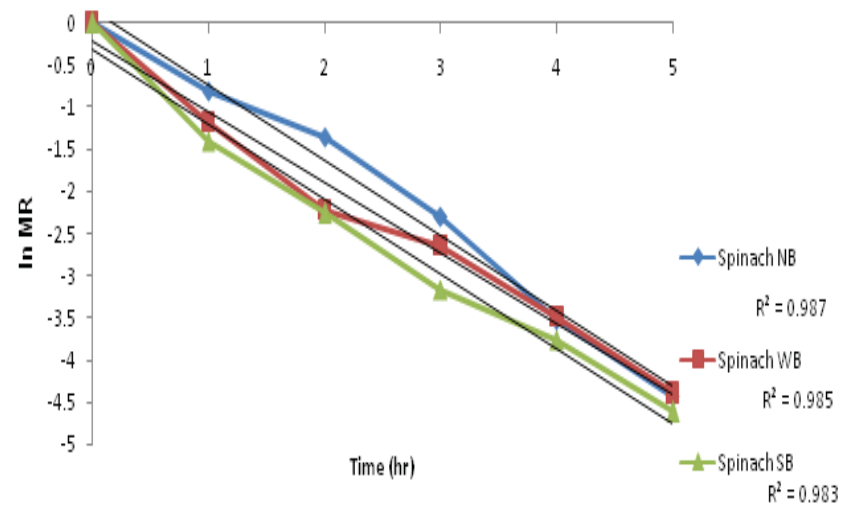

Fig 14. Newton model equation of all spinach sample [Nonblanched (Control), Water-blanching and blanching with salt solution $(2 \% \mathrm{Nacl})]$ at temperature $50^{\circ} \mathrm{C}$

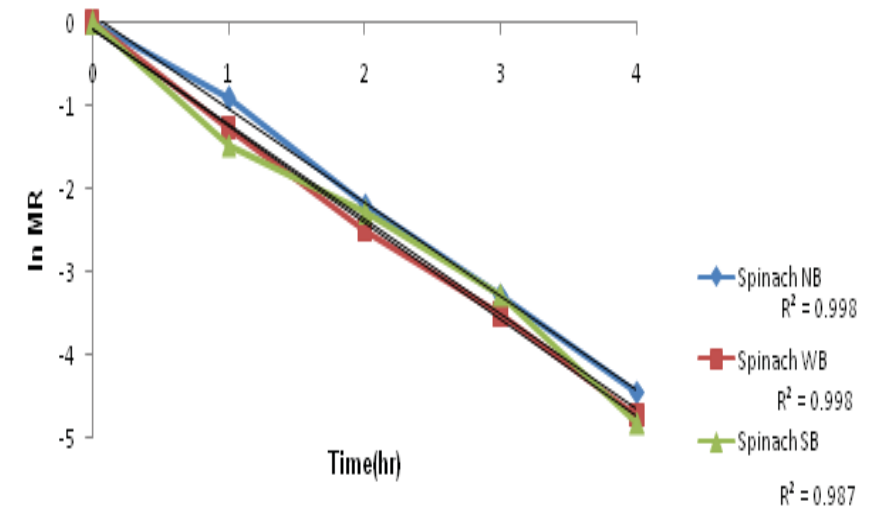

Fig 15. Newton model equation of all spinach sample [Nonblanched (Control), Water-blanching and blanching with salt solution $(2 \% \mathrm{Nacl})]$ at temperature $60^{\circ} \mathrm{C}$

Drying characteristic of spinach leaves at different temperature was studied in this work. The drying curve showed a clear exponential tendency and the formula used to simulate the experimental reading is given in table.

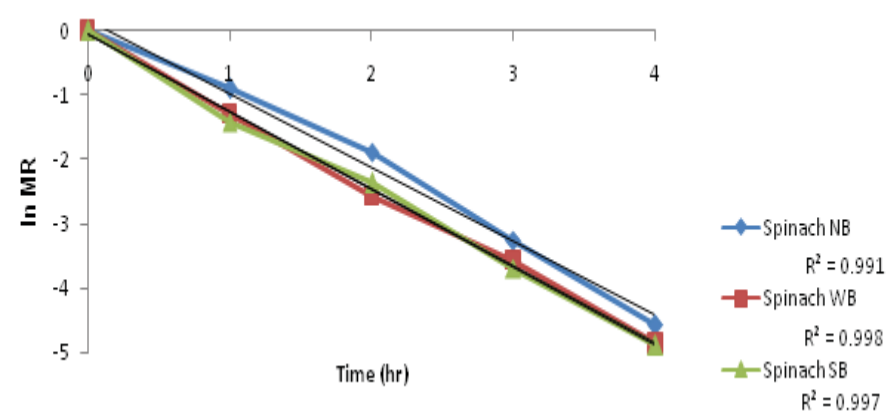

Fig 16. Newton model equation of all spinach sample [Non-blanched (Control), Water-blanching and blanching with salt solution (2\%Nacl)] at temperature $70^{\circ} \mathrm{C}$

Table 1: Newton Model Equation at different temperature

\begin{tabular}{|c|c|c|c|}
\hline Sample & NME at 50 $\mathbf{0}^{\mathbf{0}} \mathbf{C}$ & NME at 60 $\mathbf{C}$ & NME at 70 $\mathbf{C}$ \\
\hline Control & $\mathrm{MR}=\mathrm{e}^{-0.893 \mathrm{t}}$ & $\mathrm{MR}=\mathrm{e}^{-1.122 \mathrm{t}}$ & $\mathrm{MR}=\mathrm{e}^{-1.152 \mathrm{t}}$ \\
\hline $\begin{array}{c}\text { Water blanching } \\
\begin{array}{c}\text { Blanching with salt } \\
\text { solution }\end{array}\end{array}$ & $\mathrm{MR}=\mathrm{e}^{-0.837 \mathrm{t}}$ & $\mathrm{MR}=\mathrm{e}^{-1.167 \mathrm{t}}$ & $\mathrm{MR}=\mathrm{e}^{-1.200 \mathrm{t}}$ \\
\hline
\end{tabular}

\section{IV.CONCLUSION}

Dehydration process is economically beneficial for preservation of food materials. It is one of the well known methods. Drying characteristics of spinach leaves at different temperature were studied in this work. The whole drying took place in falling rate period only. We used the freeze drying technique also and observed better retention of nutritional quality than that of tray drying but it is very costly. 


\section{REFERENCES}

[1] Kris-Etherton, P.M., Hecker, K.D., Bonanome, A., Coval, S.M., Binkosru, A.E., Hilpert K.F., et al., Bioactive compounds in Foods: Their role in the prevention of cardiovascular disease and cancer. The American Journal of Medicine, 113(9,Suppliment 2) (2002): 71-88.

[2] Mattila,P.,\& kumpulainen J., Determination of free and total phenolic acid in plant derived foods by HPLC with diode array detection. Journal of Agricultural and Food chemistry,50(13),(2002): 3660-3667.

[3] Andrea Bunea,Mirjana,Andjelkovia,Carmen socaciu,Otilia Bobis,Madalina Neacsu,Roland Verke,Johr Van Camp. Total and individual carotenoids and phenolic acids content in fresh, refrigerated and processed spinach, Food Chemistry 108, (2008):649-656.

[4] Ozkau I.,Akbudak B., and Akbudak N. Microwave drying characteristics of spinach,Journal of Food Engg.,78 (2007):577-583.

[5] Dadali, G., Demirhan, E., \& Özbek, B. Colour change kinatics of spinach undergoing microwave drying. Drying Technology, 25 (2007):1713-23.

[6] Bergquist, S.A.M., Gertsson, U.E. \& Olsson,M.E, Inpulse of growth stage and post harvest storage on ascorbic acid and carotenoid content and visual quality of baby spinach(Spinacia oleracea) Journal of the science of Food and Agriculture 86(3),(2006): 346-55.

[7] Turkmen, N., Sari, F., \& Velioglu, Y. S., The effect of cooking methods on total phenolics and antioxidant activity of selected green vegetables. Food Chemistry, 93(4), (2005): 713-718.

[8] Doymaz, Í.,\&Kocayigit, F.,Drying and Rehydration Behaviors of Convection Drying of Green Peas. Drying Technology, (2011) 29, 1273- 1282. http://dx.doi.org/10.1080/07373937.2011.591713.

[9] Doymatz I,Air drying characteristic of tomatoes, Journal of Food Engineering, 78, (2007): 1291-1297.

[10] Blata.H,Wilinska,A.,Bryjak,J,Polakovic M. Thermal inactivation kinatics of vegetable peroxides, Journal of food Engg 91, (2009): $387-91$.

[11] Kardum, J.P.,Sander, A, \& Skansi, D., Comparison of convective, vacuum, and microwave drying chlorpropamide. Drying Technology, 19(1),(2011):167-183.

[12] O'Callaghan, J.R., Menzies, D.J. \& Bailey, P.H., Digital simulation of agricultural dryer performance. Journal of Agricultural Engineering Research16 (1971): 223-244.

[13] S. Ranganna., Hand Book of Analysis and Quality control for Fruit and Vegetable products (Second Edition). Tata McGraw-Hill Education, 1986.

[14] Singleton, V. L., \& Rossi, J. A.,Colorimetry of total phenolics with phosphomolybdic-phosphotungstic acid reagents. American Journal of Enology and Viticulture, 16, (1965):144-158.

[15] Benzie, I. F., \& Strain, J. J.,The ferric reducing ability of plasma (FRAP) as a measure of antioxidant power: The FRAP assay. Analytical Biochemistry, 15, (1996): 70-76.

[16] Pulido, R., Bravo, L., \& Saura-Calixto, FAntioxidant activity of dietary polyphenols as determined by a modified ferric reducing antioxidant power assay. Journal of Agricultural and Food Chemistry,48, (2000): 3396-3402.

[17] Henderson, S.M. and Pabis, S., Grain drying theory. I.Temperature effect on drying coefficient. J. Agric. Eng. Res6, (1969): $169-174$.

[18] Doymaz, I. Pretreatment effect on sun drying of mulberry fruits (Morus alba L.). Journal of Food Engineering 65(2004): 205-209

[19] Goyal, R. K., Kingsly, A. R. P., Manikantan, M. R. and Ilyas, S. M. Mathematical modelling of thin layer drying kinetics of plum in a tunnel dryer. Journal of Food Engineering 79(1) (2007): 176-180. 